\title{
Area Under Curve by UV Spectrophotometric Method for Determination Albendazole in Bulk
}

\author{
Kedar Vikas Dagdu*, Manoj Gadhave, Shubham Bhujbal, Bhushan Shrinath \\ Vishal institute of pharmaceutical education and research, Ale, Pune- 412411, India
}

\begin{abstract}
The aim of present investigation is to establish simple, precise, and rapid Spectrophotometric method for the quantification of Albendazole in Active Pharmaceutical Ingredient. In this, work is carried out to for estimation of Albendazole bulk by utilizing an Area under Curve (AUC) method using UV - Visible Spectrophotometry. The study is designed to validate the developed methods as per ICH guidelines. For this purpose the wavelength range between 200-400 nm was selected. Methanolic distilled water (50 ml methanol used for stock solution and serial dilution in $25 \mathrm{ml}$ distilled water) was used as a solvent throughout the work. Linearity was obtained in concentration range 2 to $10 \mathrm{ug} / \mathrm{ml}$ ( $\mathrm{r} 2=0.992$ ) for the method. The developed method was found to be simple, linear, accurate, precise and highly sensitive and which can be used for routine quality control analysis for Spectrophotometric estimation of Active Pharmaceutical Ingredient.
\end{abstract}

KeywordS: Albendazole, linearity, AUC, spectrophotometer, methanol, distilled water.

Article Info: Received 02 Sep 2019; $\quad$ Review Completed 11 Oct 2019; $\quad$ Accepted 19 Oct 2019; Available online 15 Nov 2019

\section{areste this article as:}

Dagdu KV, Dr. Gadhave M, Bhujbal S, Shrinath B, Area Under Curve by UV Spectrophotometric Method for Determination Albendazole in Bulk, Journal of Drug Delivery and Therapeutics. 2019; 9(6):47-50

http://dx.doi.org/10.22270/jddt.v9i6.3667

*Address for Correspondence:

Kedar Vikas Dagdu, Vishal institute of pharmaceutical education and research, Ale, Pune- 412411, India

\section{INTRODUCTION:}

A benzimidazole derivatives is broad-spectrum anthelmintic Albendazole is structurally related to mebendazole that is effective against many diseases. It is also called as (5(propylthio)-1H-benzimidazol-2-yl)carbamic acid methyl ester. Pharmacologically Albendazole is a broad-spectrum anthelmintic. The principal mechanism of action of action for Albendazole is by its inhibitory effect on tubulin polymerization which results in the loss of cytoplasmic microtubules.[1] Albendazole predominantly used in treatment of such parasite that is echinococcosis, a parasitic worm that causes cysts in liver and lung. Albendazole is practically insoluble in water and sparingly soluble in methanol. Hence the analysis of Albendazole is carried out in mixture of water and methanol. The aim of this present work is to develop simple, precise and accurate Spectrophotometric method for the routine determination of Albendazole in bulk.[2]

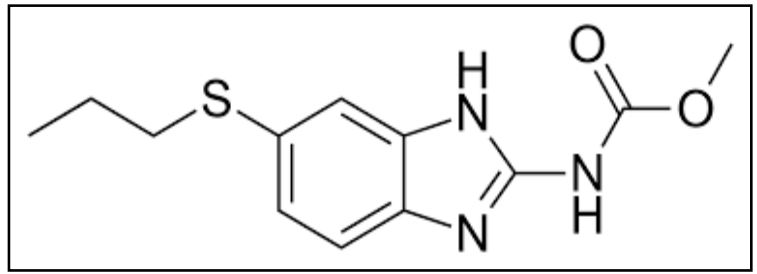

Fig no 1 structure of Albendazole

\section{MATERIALS AND METHODS:}

Chemicals:

Albendazole was obtained at collage sample of Vishal institute pharmaceuticals education and research ale, pune. Methanol, and Distilled water was used as solvent throughout the experimentation.

\section{Instrumentation:}

A Shimadzu (Kyoto, Japan) model UV- 1800 double beam UVVisible spectrophotometer attached with computer operated by software with UV probe 2.33. Spectral width of $2 \mathrm{~nm}$, wavelength accuracy of $0.5 \mathrm{~nm}$ and pair of $1 \mathrm{~cm}$ matched quartz cells was used to measure absorbance of the resulting solutions. Digital Analytical balance, Mettler Toledo (Model JL 1503-C) was used for weighing purpose.

\section{Experimental Work:}

\section{A) To check the solubility of Albendazole:}

Qualitative solubility analyses of drugs were done by dissolving $5 \mathrm{mg}$ of Albendazole in $5 \mathrm{ml}$ solvent such as distilled water, methanol and ethanol.[3]

\section{B) To identify the $K$ max of Ascorbic acid:}

Weigh10 mg of the pure drug (Albendazole) and dissolve it in small portion of methanol and make up the volume up to $100 \mathrm{ml}$ using methanol to obtained a standard stock solution 
of $100 \mu \mathrm{m} / \mathrm{ml}$ this solution is sonicate for $5 \mathrm{~min}$ to obtained clear solution. From above solution withdraw 0.5, 1, 1.5, 2, $2.5 \mathrm{ml}$ and dilute with distilled water to get standard solutions of concentrations: 2,4,6,8 and $10 \mu \mathrm{m} / \mathrm{ml} .[4,5]$ Spectrum peak details are shown in Figure No 2.

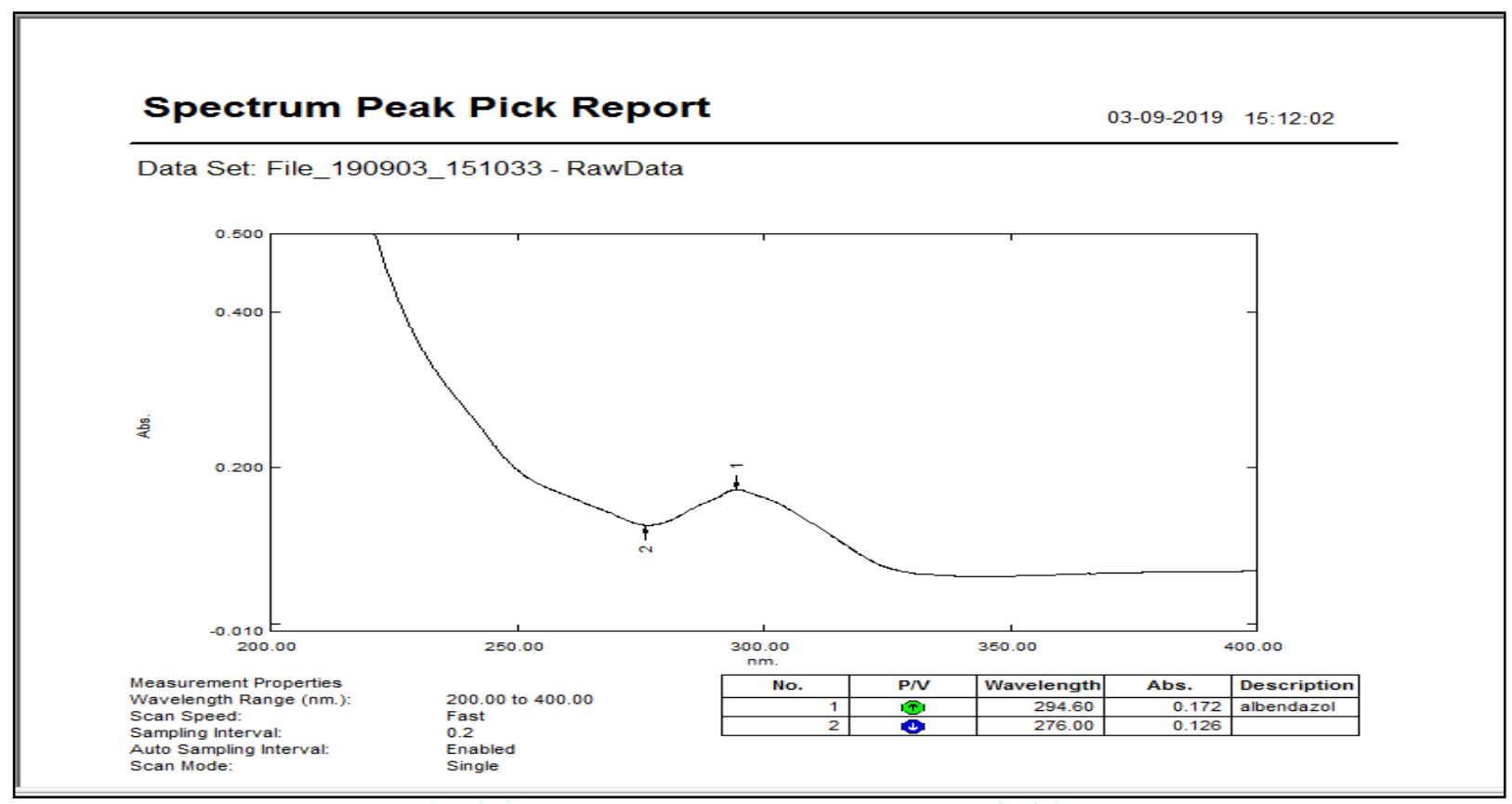

Fig no 2: $\Lambda$ max of Albendazole, Spectrum peak pick.

\section{C) Analytical Method Development and Validation:}

\section{Linearity / calibration curve:}

The linearity of an analytical procedure is the interval between the upper and lower concentration of Analyte in the sample. For which demonstrated that the analytical procedure is of linearity. The standard solution of Albendazole $(2,4,6,8$ and $10 \mu \mathrm{m} / \mathrm{ml}) 0.5,1,1.5,2$, and 2.5 $\mathrm{ml}$ solution was pipette out in a separated series of $25 \mathrm{ml}$ volumetric flask. Make up the volume with distilled water and mixed well. The absorbance maxima and area under curve for the solutions was measured at $294.6 \mathrm{~nm}$ and range of nm for two methods respectively against distilled water as blank. Calibration Curve table of Albendazole is shown in table no 1. Calibration curve of Albendazole.[6]

Table no 1 Calibration curve of Albendazole.

\begin{tabular}{|l|l|}
\hline Conc. $\boldsymbol{\mu g} / \mathbf{m l}$ & Absorbance \\
\hline 2 & 0.122 \\
\hline 4 & 0.132 \\
\hline 6 & 0.139 \\
\hline 8 & 0.149 \\
\hline 10 & 0.161 \\
\hline
\end{tabular}

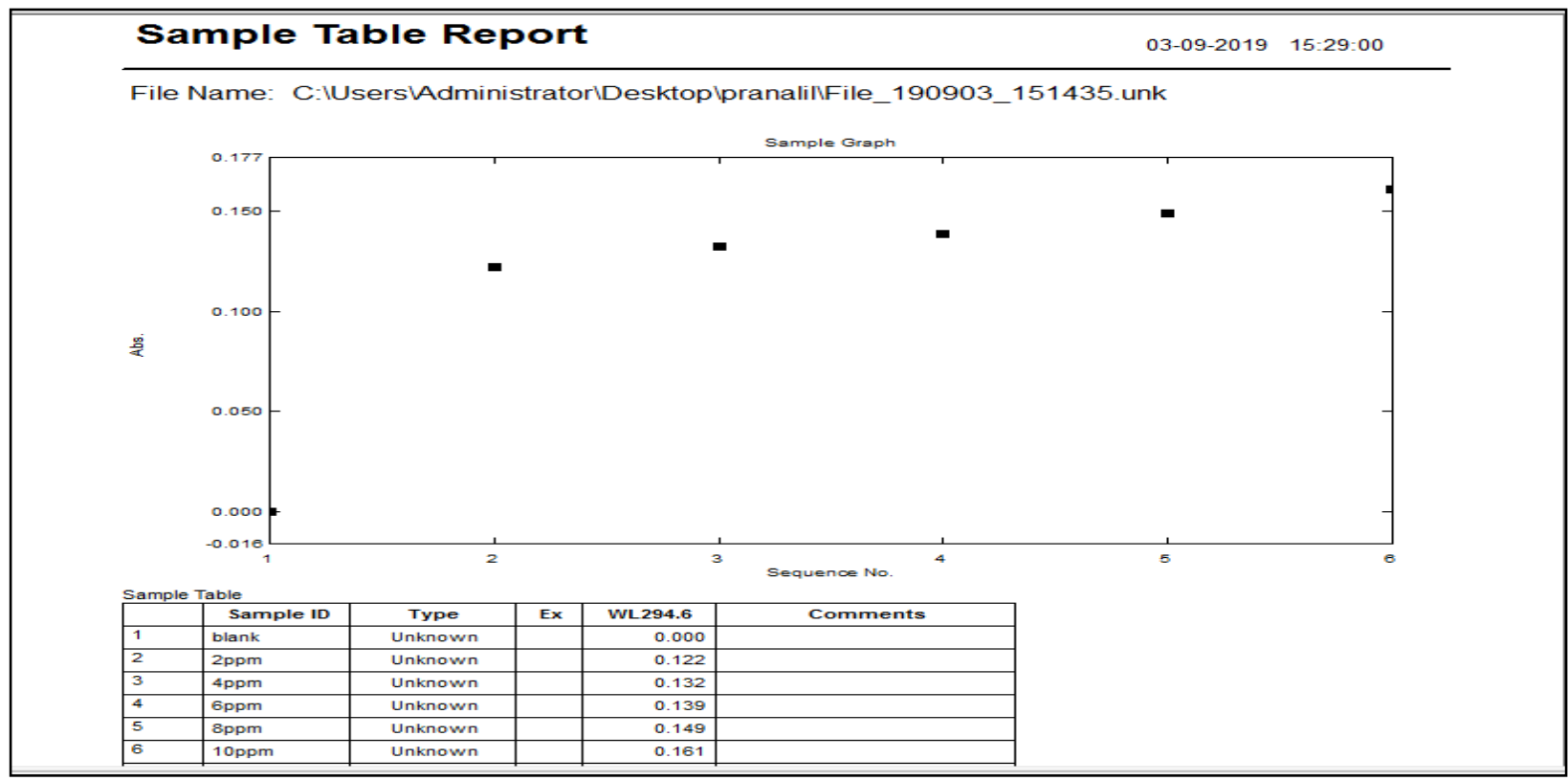

Fig No 3: linearity of Albendazole 


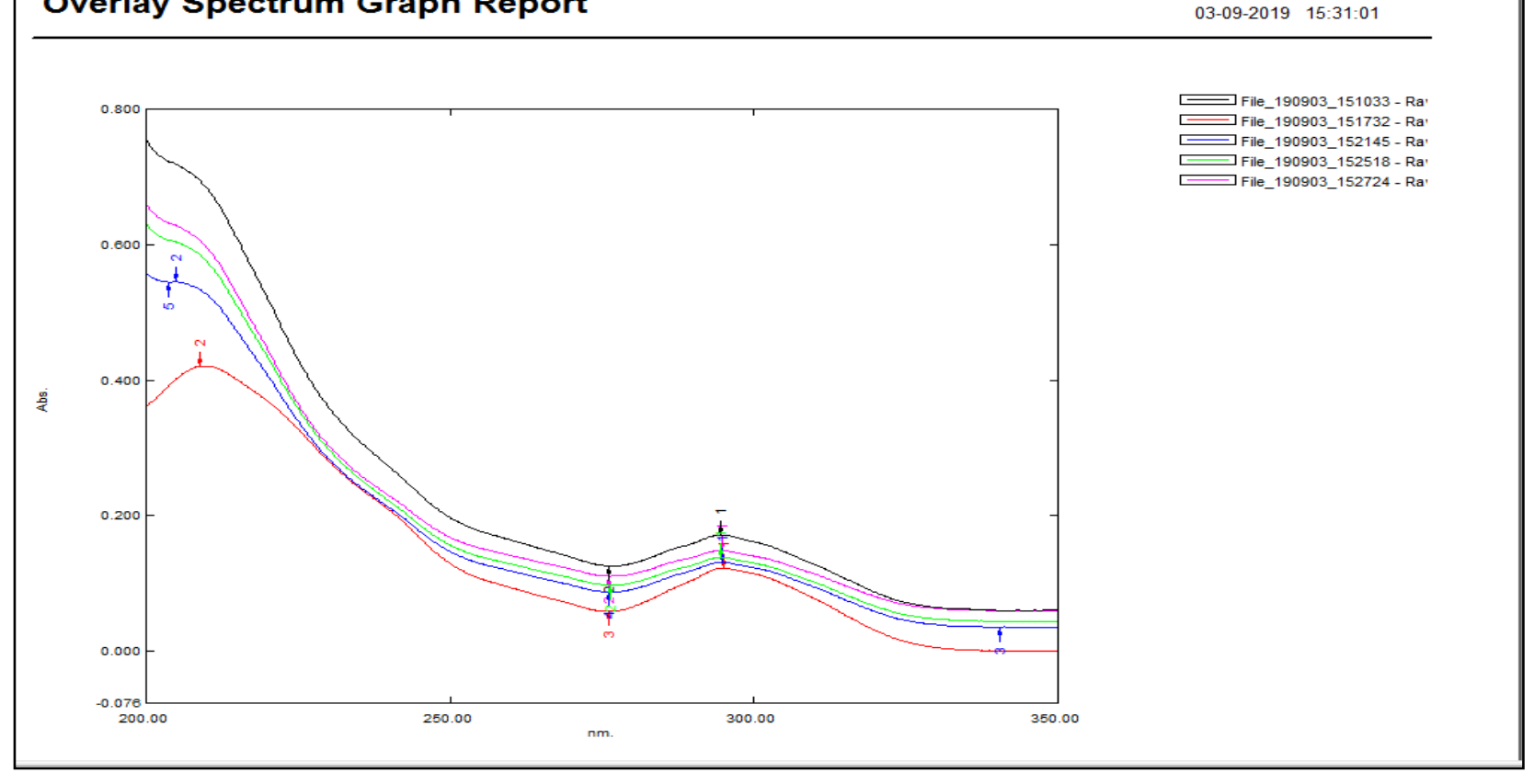

Fig no :4 overlay spectrum of Albendazole 2 to $10 \mu \mathrm{g} / \mathrm{ml}$ solution.

\section{D) Area Under Curve Method:}

In case of AUC (Area under Curve) method is applicable for there is sharp peak or broad spectra are got. It involves the calculation of integrated value of absorbance with respect to the wavelength between the two selected wavelengths $\Lambda 1$ and $\Lambda 2$. Area calculation processing item calculates the area bound by the curve and the horizontal axis. The horizontal axis is selected by the putting the wavelength ranges over which area has to be calculated. This wavelength range is selected on the basis of repeated observation so as to get the linearity between area under curve and concentration. The above mentioned spectrums were used to calculate AUC Thus, the calibration curve can be constructed by plotting concentration Vs AUC.[7]

\section{RESULTS AND DISCUSSION:}

The AUC (Area under Curve) spectra for Albendazole were recorded at the wavelength of $294.6 \mathrm{~nm}$.

\section{A] Calibration Curve for Drug:}

\section{Absorbance maxima method:}

The absorbance maxima of Albendazole were found to $294.60 \mathrm{~nm}$ in methanol + distilled water. Under the Experimental conditions described, the graph obtained for the absorbance maxima for pure drug showed linear relationship (Figure 5). Regression analysis was made for the slope, intercept and correlation coefficient values. The regression equations of calibration curve were $y=0.004 x+$ intercept $0.112 \mathrm{R}^{2}=0.992$ at $294.60 \mathrm{~nm}$ for absorption maxima the range was found to be 2 to $10 \mu \mathrm{m} / \mathrm{ml}$ by the UV Spectrophotometric analysis. Calibration Curve is shown in Table. 1. Calibration Curve of Albendazole. Calibration curve of Albendazole is shown in Figure. 4. Calibration Curve of Albendazole.

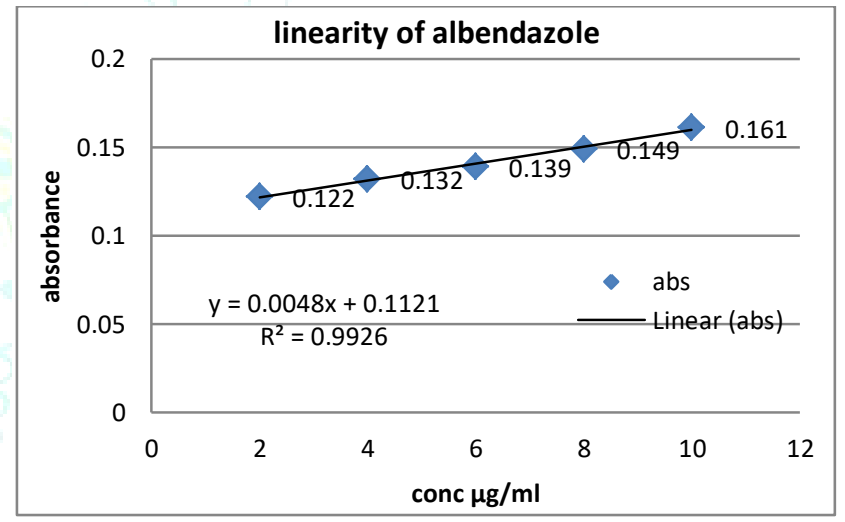

Fig No 5: Calibration curve of Albendazole

\section{B] Area Under Curve Method:}

In the Experimental conditions described, the graph obtained of the Area Under Curve (AUC) spectra shows linear relationship (Figure 6). Regression analysis was made of the slope, intercept and $\mathrm{R}^{2}$ values. The equation is $\mathrm{Y}=$ $0.004 \mathrm{x}+$ intercept $0.112 \mathrm{R}^{2}=0.992$ at $294.60 \mathrm{~nm}$ in between range $200-400 \mathrm{~nm}$ for Area Under Curve Spectrophotometry analysis. The range was found to be 2 to $10 \mu \mathrm{m} / \mathrm{ml}$ for the Area Under Curve UV Spectrophotometric analysis.

Table 2: Area Under curve of Albendazole:

\begin{tabular}{|l|l|}
\hline Parameter & AUC \\
\hline Wavelength Range $(\mathrm{nm})$ & $200-400$ \\
\hline Concentration Range $(\mu \mathrm{m} / \mathrm{ml})$ & $2-10$ \\
\hline Slope $(\mathrm{m})$ & 0.004 \\
\hline Intercept $(\mathrm{c})$ & 0.112 \\
\hline Correlation Coefficient $(\mathrm{r} 2)$ & 0.992 \\
\hline
\end{tabular}




\section{Spectrum Peak Area Report}

03-09-2019 15:33:45

Data Set: File_190903_151033 - RawData

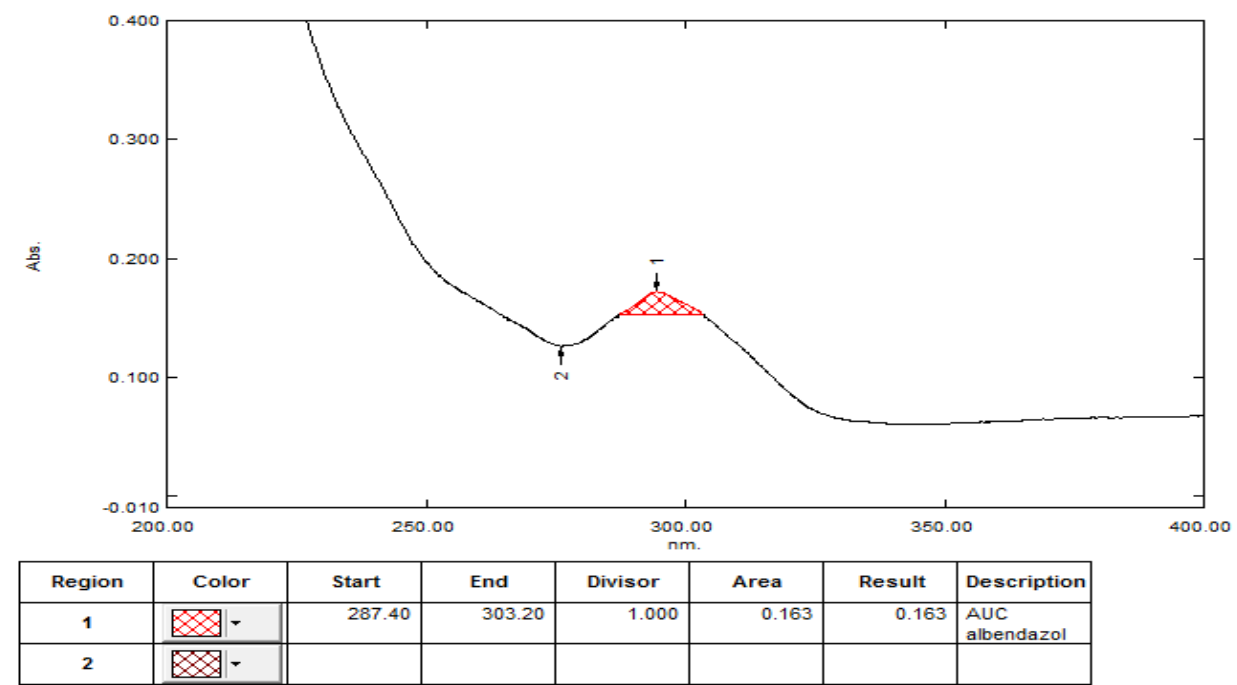

Fig no 6: Area Under Curve of Albendazole

\section{CONCLUSION:}

There is no any Spectrophotometric methods have been described for AUC determination of Albendazole. Therefore simple, fast and precise method for area under curve was developed by UV spectrophotometrically for the routine analysis of Albendazole. The developed

Method can be concluded as simple, accurate, sensitive and precise and can be easily applicable in the pharmaceutical formulation.

\section{ACKNOWLEDGRMENT:}

The authors are thankful Vishal Institute of pharmaceutical education and research, Ale, Pune, for constant motivation and also for providing Albendazole standard drug sample. We would like to thank our principal Dr. Jadhav S. L. for providing us suitable environment for this work.

\section{REFERENCES:}

1. https://www.drugbank.ca/drugs/DB00518

2. https://pubchem.ncbi.nlm.nih.gov/compound/Albendazole

3. Shivani Kala and Divya Juyal; Preformulation and characterization studies of aceclofenac active ingredient; The Pharma: 463- Innovation Journal 2016; 5(9): 110-119.

4. Beckett, A. H., Stenlake, J. B., Practical Pharmaceutical Chemistry, 4th edition, CBS Publishers and Distributors, New Delhi, 2002; 2: 275-295.

5. Rajaiya Prashant, Mishra Rakesh, Nandgude Tanaji*, Poddar Sushilkumar, Solubility and Dissolution Enhancement of Albendazole by Spherical Crystallization, ajbps. 2016, 6(52),09-14.

6. Christian G D. Analytical chemistry 6th edition, John Willey and Sons, PA, 1-2,604-620, 2003.

7. Blessy M. A review - development and stability indicating studies. Journal of Pharmaceutical Analysis, 2013. 